\title{
Visual Outcome of Phacoemulsification Versus Small Incision Cataract Surgery
}

\author{
Narain Das ${ }^{1}$, Asma Shams ${ }^{2}$, Jai Kumar ${ }^{3}$, Beenish Khan ${ }^{4}$, Nasir Bhatti ${ }^{5}$ \\ ${ }^{1,2,3,5}$ Department of Ophthalmology, Shaheed Mohtarma Benazir Bhutto Medical College, Layari Karachi \\ ${ }^{4}$ Department of Ophthalmology, United Medical \& Dental College, Karachi
}

\begin{abstract}
Purpose: To determine visual rehabilitation of Phacoemulsification in comparison to small incision cataract surgery (SICS) after implantation of rigid intraocular lens.
\end{abstract}

Study Design: Quasi Experimental Study.

Place and Duration of Study: Shaheed Mohtarma Benazir Bhutto Medical College Lyari and Sindh Government Lyari General Hospital, Karachi, from July 2018 to December 2019.

Methods: Patients aged $35-70$ years and diagnosed with senile cataracts and visual acuity of $\leq 6 / 36$ were included. Patients having any corneal disease, intra-ocular pressure $>22 \mathrm{~mm} \mathrm{Hg}$, high ametropia, any other eye disease were excluded. Patients were divided into two groups of 80 patients each. Group I underwent Phacoemulsification and group II had Small incision cataract surgery. For data analysis, SPSS version 20.0 was used. Frequency and percentages were calculated for qualitative data and quantitative data was presented as mean and standard deviation.

Results: In total 160 patients underwent cataract surgery. There were equal male and female patients. The range of astigmatism after 6 months in the group I was between $0.5-1.00 \mathrm{D}$ while in the group II, it was between $0.75-1.75 \mathrm{D}$. Uncorrected visual acuity and best corrected visual acuity of $6 / 18$ or better was seen at 1 month and 6 months in $88 \%$ and $97 \%$ group 1 while it was $85 \%$ and $95 \%$ in group II patients.

Conclusion: No significant difference was seen in uncorrected and best corrected visual acuity between the two groups. Time of surgery was lesser in patients undergoing SICS while astigmatism was lesser in phacoemulsification group.

Key Words: Phaco-emulsification, Small Incision Cataract Surgery, Visual Rehabilitation.

How to Cite this Article: Das N, Shams A, Kumar J, Khan B, Bhatti N. Visual Outcome of Phacoemulsification Versus Small Incision Cataract Surgery. Pak J Ophthalmol. 2021, 37 (1): 83-87.

Doi: https://doi.org/10.36351/pjo.v37i1.1140

Correspondence: Narain Das

Department of Ophthalmology

Shaheed Mohtarma Benazir Bhutto Medical College

Layari Karachi

Email: narainpagarani@yahoo.com

Received: September 29, 2020

Accepted: November 30, 2020

\section{INTRODUCTION}

Cataract is one of the most important and leading cause of preventable blindness especially among the older, senile population. It is common throughout the world. $^{1} \quad$ Latest cataract surgery using modern technologies with intra-ocular lens (IOL) implant is regarded as the safest, simple, highly successful, and commonly performed cataract surgery. ${ }^{2}$ The use of small incision cataract surgery (SICS) has gained much popularity as compared to Phaco-emulsification (PHACO) especially in developing countries. SICS is more cost-effective than Phaco-emulsification. However, both Phaco and SICS have benefits such as early post-operative visual rehabilitation, decreased induced astigmatism as well as minimal suture-related 
complications such as toxic suture syndrome. ${ }^{3}$ Expectations for both the patient as well as the surgeon have increased owing to the fact that with astounding advancements in technology and predictability, the outcomes of surgeries have increased as well. The main aim of the surgeons is to meet the patient's individual needs with optimum refractive goal and patient expectation for improved vision without needing the use of spectacles especially at immediate post-operative time period. ${ }^{4}$ Post-operative complications such as refractive errors following cataract surgery have become almost absent in the recent years. Subsequently, the surgeries for cataract have overcome surgeries for refractive errors leading to an improvement in both the "uncorrected" and "best corrected" visual acuity as well. ${ }^{5}$ Cataract surgery is an elective surgery, however most patients from low socio-economic background residing in rural areas tend to be operated in free medical camps. Since SICS, being a faster, safer and non-invasive non-machine dependent surgery, is the most preferred options by the surgeons in such settings while in more advanced centers having state-of-the-art technologies, Phacoemulsification remains the routinely performed surgery. ${ }^{6}$ Nonetheless, most patients from rural areas are lost to follow-up, which are a key factor in postoperative visual rehabilitation, post-operative precautions as well as treatment of complications. ${ }^{7}$

Even though the number of cataract surgeries has increased since the initiative of WHO Vision 2020, poor vision outcome after surgery remains one of the major concerns. ${ }^{8}$ Population based researches in Latin America, Africa and Asia have reported a minimum of $20 \%$ post-operative cataracts to present with a $<6 / 60$ vision. ${ }^{9}$ Any treatment or surgery which could improve visual outcomes after surgery is vital in contributing to Vision 2020. Phaco-emulsification following foldable IOL is the surgery of choice in high-income countries. ${ }^{10}$ Small incisions lead to reduction in astigmatism with improved and better visual outcomes following the procedure. Among middle and low-income countries, researches on SICS versus Phaco have reported variations in results. ${ }^{11}$ Equipment needed for Phaco is costly and therefore not commonly used in low-income areas. Clinical observations have suggested implants of inexpensive rigid IOL following Phaco to attain similar visual outcomes compared to the use of more expensive foldable IOLs. ${ }^{12}$ Phaco and SICS surgeries in terms of visual outcome of patients, safety of the lenses, intra- operative and post-operative complications and finally the cost of the whole procedure are all important aspects of cataract surgeries. ${ }^{13}$

The objective of this study was to determine the visual rehabilitation of Phacoemulsification in comparison to small incision cataract surgery after implantation of rigid intraocular lens and also to report its safety and effectiveness.

\section{METHODS}

This prospective study using non-probability convenient sampling technique was carried out for a period of 1.5 years at the Ophthalmology department of Shaheed Mohtarma Benazir Bhutto Medical College, Lyari General Hospital, Karachi. After ethical approval from the respective Institutional Review Board (IRB), a total of 160 patients were selected from the Ophthalmology OPD of Lyari General Hospital, Karachi from $1^{\text {st }}$ July 2018 to $1^{\text {st }}$ Dec 2019. After written and informed consent, patients presenting to the Eye OPD between $35-70$ years and diagnosed with age-related cataract having visual acuity of $6 / 36$ or less in eye to be operated were included in the study. Patients having any corneal disease, intra-ocular pressure $>22 \mathrm{~mm} \mathrm{Hg}$, high ametropia, and any other eye disease or diabetes mellitus were excluded from the study. All the patients were explained about the procedure they were about to undergo and were counseled for possible post-operative complications.

The patients were divided into two groups of 80 each, one group underwent Phaco and the other group SICS. Patients in Phaco group were operated via a clear corneal superior incision (about 11 O'clock) of $2.8 \mathrm{~mm}$, that was enlarged to around $5.2 \mathrm{~mm}$ and rigid $5.25 \mathrm{~mm}$ lens was then implanted. In the SICS group, superior straight $1.5 \mathrm{~mm}$ incision from limbus was made which was extended to $5.5-6.5 \mathrm{~mm}$ with 5.25 $\mathrm{mm}$ IOL implantation. All the operations were performed by the same surgeon. Operative time in patients undergoing either of the procedures was noted. All the patients were followed up on day one, 1 month and at 6 months after surgery. Patients were compared in both the groups in terms of post-operative un-corrected visual acuity (UCVA), best-corrected visual acuity (BCVA), frequency of astigmatism and the visual outcomes at each respective follow-up.

SPSS version 20.0 was used for data analysis. Qualitative data of gender, uncorrected and bestcorrected visual acuity was reported as frequency and 
percentages while quantitative data was presented as mean and standard deviation.

\section{RESULTS}

Total of 160 patients were recruited in the study and were divided into two groups. In group I, 35 (44\%) patients were male while $45(56 \%)$ patients were female. In group II, $36(45 \%)$ of the patients were male while $44(55 \%)$ of the patients were female The mean operating time taken for small incision cataract surgery procedure was comparatively lesser than for Phacoemulsification (Phaco). The range of astigmatism after 6 months in group-I was reported between $0.5-1.00$ Diopters while in group-II it was between $0.75-1.75 \mathrm{D}$. Poor visual outcome of $6 / 60$ or worse was seen in 3\% in group-I and 5\% in group-II. At the first post-operative day, the BCVA of $6 / 18$ or better was seen in $73 \%$ in group-I and $60 \%$ in groupII. For further follow-ups see graph 1.

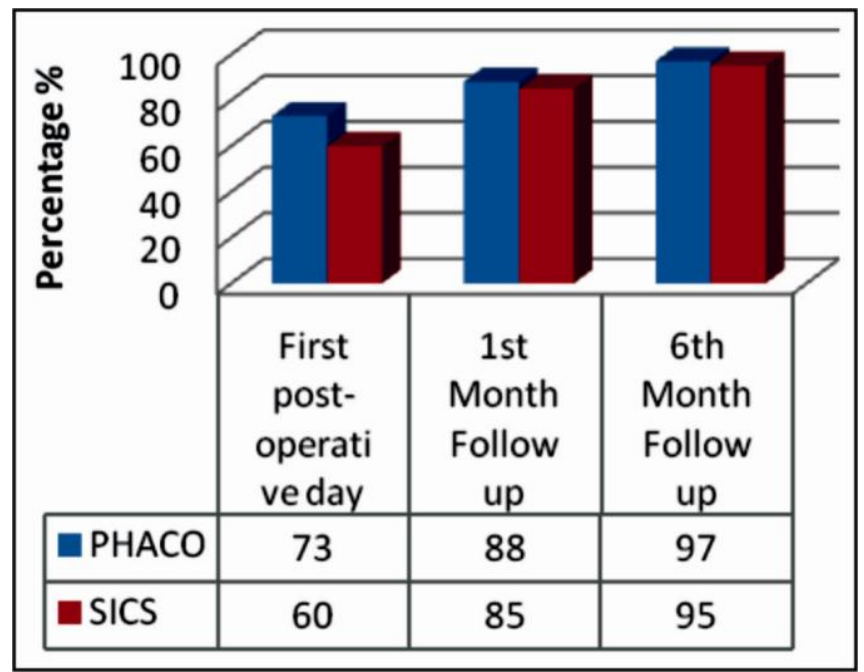

Graph 1: Showing Best Corrected Visual Acuity of $6 / 18$ or better at serial follow-ups.

\section{DISCUSSION}

Cataract continues to be the main reason for impairment of vision in Pakistan. Since most of the population resides in the low-income areas, many of the patients tend to undergo for cheaper surgical methods. Due to the fact that majority of the patients of cataract are elderly and illiterate they have a mindset of cheapest and quickest method of cataract treatment/surgery. ${ }^{14}$ Cataract surgeries are of high volume and in order to ensure that patients adhere to proper follow-ups and medicinal/hygiene needs, continuous supervision as well as higher vigilance on part of health professionals is necessary. Both groups Phaco and SICS have been regarded as good options even in high volume surgical areas. Rigid IOLs are reported to be cost-effective in comparison to foldable IOLs. In such case, any surgical option, which is not only safe, faster as well as provides an optimum visual outcome should be the preferred method. ${ }^{15}$

According to the results of this study, the reported UCVA and BCVA at $1^{\text {st }}$ post-operative day, follow up at $1^{\text {st }}$ and $6^{\text {th }}$ month between Phaco and SICS groups were found to be more of less the same, so no significant difference was reported between both the groups. Likewise, many other studies have also observed similar findings. Jaggernath et al in his study compared Phaco and SICS. He reported that both the techniques presented similar trends in visual outcomes where $98 \%$ of patients in both the groups achieved BCVA of $6 / 18$ or better at the $6^{\text {th }}$ month follow-up. However, he also concluded that SICS was superior to Phaco is terms of significant time-line in visual rehabilitation, cost-effectiveness and lesser dependency on technology. ${ }^{16}$

Gogate et al in another study in which Phaco and SICS were compared reported that both the procedures were safe as well as effective in visual rehabilitation in patients of cataracts. The study recorded BCVA of $6 / 18$ or better in $98.4 \%$ of patients in both the groups at follow-up on $6^{\text {th }}$ post-operative week. However, Phaco provided improved UCVA in more number of patients than with SICS. ${ }^{17}$ Gogate et al reported that no significant difference in time of surgery as well as intra and post-operative complications were found in either of the groups. However, in both the groups, UCVA of the patients did not improve substantially. Another study reported that SICS had better UCVA than Phaco. ${ }^{18}$ Comparable reports of BCVA and UCVA showed that intra and post-operative complications such as endothelial cell loss makes SICS an equivalent technique when compared with PHACO.${ }^{19}$ It is important to note that Phaco has an advantage of smaller size of incision as compared to SICS procedure. The incidence of post-operative astigmatism is reported to be substantially low in Phaco. $^{20}$

Surgical time-period is reported to be lower in SICS as compared with Phaco. Furthermore, in SICS rigid IOL is used most of the times, which is cheaper than the foldable IOL. This makes the cost of SICS 
further less making SICS a more preferred option especially in low-income areas. ${ }^{21,22}$

Although no significant differences have been found in terms of immediate post-operative complications or in long-term complications of in either of the two techniques, astigmatism was lesser in Phaco group as compared to SICS. A study reported that although there was no significant difference in post-operative visual acuities of the patients that underwent either Phaco or SICS, post-operative astigmatism was substantially higher in the SICS group having rigid IOL implantation than in PHACO with rigid IOL implantation. ${ }^{23}$ Likewise, Mahayana et al also observed similar results, reporting a mean astigmatism of $0.98 \mathrm{D}$ in the Phaco group while 1.45 $\mathrm{D}$ in SICS group. ${ }^{24}$ In line with our study, Iqbal et al reported slightly higher astigmatism in SICS group as compared to Phaco group. ${ }^{25}$

Limitation of our study was that only Phaco and SICS were compared. Comparison of different types of lenses was also not made. It was a single-center study. Multi-centered studies on a larger scale with greater sample size would be enlightening in determining the differences of Phaco and SICS among a variety of patients.

\section{CONCLUSION}

Even though no significant difference existed in terms of uncorrected visual acuity and best corrected visual acuity, time for surgery was lower in patients with small incision cataract surgery while in patients with Phacoemulsification, astigmatism was less frequent.

\section{Ethical Approval}

The study was approved by the Institutional review board/ Ethical review board.

(F-SMBBMCL/(ERC)/2020-20/156)

\section{Conflict of Interest}

Authors declared no conflict of interest.

\section{REFERENCES}

1. Ali AM, Abdulla AM, Howaidy AI, Mohammed RM. Comparative Study between The Refractive Outcome Following Phacoemulsification and Small Incision Cataract Surgery. Egypt J Hosp Med. 2019; 76 (1): 30373038 .
2. Moodley S, Alberto K. Visual outcomes in manual small incision cataract surgery versus phacoemulsification: a prospective comparative data analysis. South Afr Ophthalmol J. 2019; 14 (3): 21-24.

3. Bhandari A, Bhandari D. Comparative study of visual outcome in eyes following phacoemulsification and in eyes following manual small incision cataract surgery. Ind J Bas Appl Med Res. 2019; 8 (2): 11-17.

4. Jian Z, Chun-ping L. Comparison of improved phacoemulsification through limbus tunnel incision versus manual small-incision cataract surgery on ophthalmic operation vehicle. Intern Eye Sci. 2017; 17 (11): 2085-2088.

5. Pant SR, Bhatta RC, Awasthi S. Post-Operative Astigmatism and Visual Outcome among Superior Approach Manual Small Incision Cataract Surgery at Surgical Eye Camp in Nepal. J Clin Exp Ophthalmol. 2019; 10 (807): 2-5.

6. Kanellopoulos AJ, Asimellis G. Standard manual capsulorhexis/ultrasound phacoemulsification compared to femtosecond laser-assisted capsulorhexis and lens fragmentation in clear cornea small incision cataract surgery. Eye and Vis. 2016; 3 (1): 20-25.

7. Kaur T, Singh K, Kaur I, Kaur P, Chalia D. A comparative study of endothelial cell loss in cataract surgery: small incision cataract surgery versus phacoemulsification. Ind J Clin Exp Ophthalmol. 2016; 2 (4): 318-322.

8. Signes-Soler I, Javaloy J, Munoz G, Moya T, Montalban R, Albarran C. Safety and efficacy of the transition from extracapsular cataract extraction to manual small incision cataract surgery in prevention of blindness campaigns. Middle East Afr J Ophthalmol. 2016; 23 (2): 187-194.

9. Sharma N, Vandana PS. To compare post-operative astigmatism in temporal clear corneal incision phacoemulsification and temporal manual small incision cataract surgery. Ind J Clin Exp Ophthalmol. 2017; 3 (2): 177-179.

10. Mittal R, Peter J, Mani T, David S. Visual outcome and patient satisfaction after cataract surgery: A pragmatic study. Clin Epidemiol Glob Health, 2019; 7 (3): 509-512.

11. Hamid KA, Habibullah S. Comparison of visual outcomes in patients undergoing small incision cataract surgery versus phacoemulsification at Divisional Headquarters Hospital, New Mirpur, Azad Kashmir. Professional Med J. 2019; 26 (08): 1365-1369.

12. Chu L, Zhao JY, Zhang JS, Meng J, Wang MW, Yang YJ, et al. Optimal incision sites to reduce corneal aberration variations after small incision phacoemulsification cataract surgery. Intern $\mathbf{J}$ Ophthalmol. 2016; 9 (4): 540-545. 
13. Saif MY, Saif AT, Saif PS, Abdel Khalek MO, Mahran W. Dry eye changes after phacoemulsification and manual small incision cataract surgery (MSICS). Int J Ophthalmol Eye Res. 2016; 4 (2): 184-191.

14. Donaldson K, Fernandez-Vega-Cueto L, Davidson R, Dhaliwal D, Hamilton R, Jackson $M$, et al. Perioperative assessment for refractive cataract surgery. J Cat Refract Surg. 2018; 44 (5): 642-653.

15. Li S, Jie Y. Cataract surgery and lens implantation. Curr Opin Ophthalmol. 2019; 30 (1): 39-43.

16. Jaggernath J, Gogate P, Moodley V, Naidoo KS. Comparison of cataract surgery techniques: safety, efficacy, and cost-effectiveness. Eur J Ophthalmol. 2014; 24 (4): 520-526.

17. Gogate P, Optom JJ, Deshpande S, Naidoo K. Metaanalysis to compare the safety and efficacy of manual small incision cataract surgery and phacoemulsification. Middle East Afr J Ophthalmol. 2015; 22 (3): 362-369.

18. Gogate P, Ambardekar P, Kulkarni S, Deshpande R, Joshi S, Deshpande M. Comparison of endothelial cell loss after cataract surgery: phacoemulsification versus manual small-incision cataract surgery: six-week results of a randomized control trial. J Cat Refract Surg. 2010; 36 (2): 247-253.

19. Ramalakshmi V, Rani MRH, Rajalakshmi A, Anandan H. Comparison of Merits and Demerits of Manual Small Incision Cataract Surgery with Phacoemulsification. Int J Sci Stud. 2017; 4 (12): 161163.

20. El-Sayed SH, El-Sobky HM, Badawy NM, El-Shafy EA. Phacoemulsification versus manual small incision cataract surgery for treatment of cataract. Meno Med J. 2015; 28 (1): 191-196.

21. Harakuni U, Bubanale S, Smitha KS, Tenagi AL, Kshama KK, Meena A, et al. Comparison of surgically induced astigmatism with small incision cataract surgery and phacoemulsification. J. Evol. Med. Dent. Sci. 2015; 4 (71): 12354-12360.
22. Ali AM, Abdulla AM, Howaidy AI, Mohammed RM. Comparative Study between The Refractive Outcome Following Phacoemulsification and Small Incision Cataract Surgery. The Egypt J Hosp Med. 2019; 76 (1): 3037-3038.

23. Devendra J, Agarwal S, Singh PK. A comparative study of clear corneal phacoemulsification with rigid IOL versus SICS; the preferred surgical technique in low socio-economic group patients of rural areas. J Clin Diag Res. 2014; 8 (11): 1-4.

24. Mahayana IT, Setyowati R, Winarti T, Prawiroranu S. Outcomes of manual small incision cataract surgery (mSICS) compared with phacoemulsification from population based outreach eye camp, in Yogyakarta and Southern Central Java Region, Indonesia. J Comm Emp Health, 2018; 1 (1): 6-10.

25. Iqbal S, KV SM, Menon A, Krishnan P, Latheef $\mathbf{N}$, Kiran KR. A prospective comparative study of visual outcome and complications in small incision cataract surgery and phacoemulsification. Nat J Med All Sci. 2015; 4 (1): 50-55.

\section{Authors' Designation and Contribution}

Narain Das; Assistant Professor: Concepts, Design.

Asma Shams; Senior Registrar: Literature search, Data acquisition.

Jai Kumar; Postgraduate Trainee: Data analysis, Statistical analysis.

Beenish Khan; Assistant Professor: Manuscript preparation, Manuscript editing.

Nasir Bhatti; Professor: Manuscript review. 